Article

\title{
The Optimal Production Decision of Competing Supply Chains When Considering Green Degree: A Game-Theoretic Approach
}

\author{
Jiguang Wang ${ }^{1, * \mathbb{C}}$, Jianhong Chang ${ }^{1}(\mathbb{D})$ and Yucai $\mathrm{Wu}^{2, *(\mathbb{D}}$ \\ 1 School of Economics \& Management, Shanxi University, Taiyuan 030006, China; \\ 201823807001@email.sxu.edu.cn \\ 2 Faculty of Business Administration, Shanxi University of Finance \& Economics, Taiyuan 030006, China \\ * Correspondence: wangjg@sxu.edu.cn (J.W.); wuyucai@sxufe.edu.cn (Y.W.); \\ Tel.: +86-139-3458-4285 (J.W.); +86-159-3512-1373 (Y.W.)
}

Received: 27 July 2020; Accepted: 7 September 2020; Published: 9 September 2020

check for updates

\begin{abstract}
Nowadays, the green supply chain has become an exciting concept in academic societies. This paper focuses on the optimal production decisions of two competing supply chains from the perspective of green degree. The manufacturers in each supply chain have two options-producing a green product or a non-green product. Game theory is applied to study four decision scenarios, which are derived from the difference in the products of the two supply chains. This study investigates the influence of inter-supply-chain competition on the wholesale price, green degree, and profits of the supply chain members. The results indicate that the inter-supply-chain competition has a negative correlation with the wholesale price. The inter-supply-chain competition has a significant impact on green degree in the four decision scenarios. In addition, green products are not always the dominant strategy of manufacturers. Both the competitors' product decisions and the degree of inter-supply-chain competition should be considered. Finally, weak inter-supply-chain competition is beneficial to the leader supply chain, while strong competition is beneficial to the follower supply chain.
\end{abstract}

Keywords: inter-supply-chain competition; green degree; production decision; game theory

\section{Introduction}

Due to the intensifying issue of the global environment, as well as increases in consumers' environmental awareness, green supply chain management (GSCM) has gained growing scrutiny in recent years within both academia and industry [1-3]. Environmental sustainability has become a supply chain imperative rather than only an organizational imperative, as well as an essential metric for evaluating a supply chain's success [4,5]. Accordingly, shifting to a sustainable mode by producing green products in a green way has become a popular trend in business practice [6]. Green supply chains are considered to be the future direction of supply chains. An increasing number of leading branding firms are now proactively implementing "green" initiatives or policies to generate more business opportunities and to improve competitiveness for firms [7]; for example, Adidas, IKEA, IBM, HUAWEI, GREE, Lenovo, BYD, and GE. As one of the important factors of greening initiatives, green products play a vital role in the development of GSCM with respect to decision-making processes. Thereby, this widely accepted concept contributes to the increasing research on green product decisions within a supply chain.

There is a large amount of literature on supply chain management (SCM) focused on greenness issues through the emerging concept GSCM. Moreover, GSCM goes beyond core SCM issues to 
focus on environmental issues. According to the most recent comprehensive review on GSCM, the following topics relate to "greenness": e.g., procurement, green product decision, green operations, green technology, green subsidies, reverse logistics, and remanufacturing [3,8-10]. From this perspective, our research falls in the domains of both green product decision and green operations under supply chain settings. Based on observations and analysis, we try to answer these questions: (1) Will such green product efforts ultimately translate into improved supply chain performance? If so, are there some prerequisites for such improvement? (2) Is the green product decision always the manufacturer's dominant strategy in the context of inter-supply-chain competition? If not, what are the conditions? (3) How does the inter-supply-chain competition affect wholesale price, green degree, and profits of the supply chain members?

These questions have important theoretical and practical significance. In this paper, we attempt to answer these questions. Accordingly, an analytical model of two competitive two-stage supply chains, which include one manufacturer and one retailer, is developed. The manufacturers in each supply chain have two options-producing a green product or a non-green product. Meanwhile, to encourage manufacturers to produce green products, the government subsidizes manufacturers according to the level of greenness of the supply chain. Two types of competition-price competition and green degree competition-are considered. Therefore, four decision scenarios, which are derived from the difference in products of the two supply chains, are intended to explore the optimal price and green degree, the dominant strategy of manufacturers, and the influence of inter-supply-chain competition on the supply chain members' profits. There is consensus that today's competition is no longer just between firms, but also among supply chains $[6,10]$. This study argues that it is of great significance to consider greenness and inter-supply-chain competition in the context of GSCM.

In this paper, we make the following contributions: (1) In this paper, two types of competitioninter-supply-chain price competition and green degree competition-are considered simultaneously to investigate the influence on manufacturers' product decisions. To the best of our knowledge, the extant literature largely focused on intra-supply-chain competition. (2) In this study, a dual Stackelberg game is established, that is, both inter- and intra-supply chain adopt the Stackelberg game, and both sides are competitive. This consideration is also extremely consistent with the real production operation, and is of great significance in academic and practical aspects. (3) This paper is different from the existing literature in the forms of government subsidies used. Most literature uses the form of fixed subsidies, whereas this paper proposes a novel subsidy form based on green degree, which further enriches the study in this field.

This paper is organized as follows. In Section 2, we give a brief review of relevant literature. Section 3 introduces the notations, assumptions, and the basic model. In Section 4, the game model and solutions are presented in four scenarios. The following Section 5 presents the theoretical results and comparisons of these results. Then, Section 6 provides numerical experiments and sensitivity analyses. Finally, in Section 7, we discuss the conclusion, as well as future research directions of this work.

\section{Literature Review}

The main focus of SCM is to provide the right product to the right customers in the right manner. In the presence of environmentally aware consumers, regulations, competitor pressures, and social responsibilities, the "green" component is added into the SCM practices. GSCM practices encompass a set of green activities in procurement, manufacturing, distribution, and reverse logistics [11,12]. GSCM is a type of developed supply chain management that is concerned with being green, maintaining a stable environment, waste reduction, and optimum use of resources [13]. Furthermore, supply chains can acquire competitive advantage by being the first to implement GSCM practices. In academia, the emerging field of GSCM has been rapidly progressing in the number of academic publications in this field. As discussed above, there is a large body of literature related to our study from different research areas. Interdisciplinary research has integrated the efforts of management, engineering, physical, and social sciences to investigate the issues relevant to this topic [14,15]. In particular, the related 
literature could be categorized into three streams: (1) green supply chain and consumers' green preferences; (2) green-degree-related research on SCM; (3) production and operation decisions in GSCM. In the following section, we review studies relevant to each stream and highlight the differences between this study and the existing literature.

The first stream of research is mainly about theoretical and policy research on GSCM [11]. The research on GSCM has been developing noticeably during the last two decades. GSCM is increasingly a concern for many business organizations and a challenge for logistics management in the 21st century. According to a global survey by Accenture, more than $80 \%$ of respondents consider product greenness when making a purchase decision [5]. Consumer environmental awareness is a critical market-driven factor that facilitates GSCM. Madani and Rasti-Barzoki [6] pointed out that the growing awareness of the adverse effect of environmental issues has led governments and social organizations to put pressure on core producers in supply chains to adopt green production methods. Furthermore, with the rise of consumer environmental awareness, it is expected that the consumption of environment friendly products out of consideration for the environment and human health will increase [1]. Therefore, people's living style is changing into a green lifestyle. Despite paying higher prices, they still prefer to buy green products instead of the usual ones. Green et al. [4] argues that the adoption of GSCM practices by manufacturers leads to improved environmental performance and economic performance, which, in turn, positively impact operational performance. Considering a hybrid-product (traditional and green product) supply chain when demand is a function of consumer environmental awareness, Liu et al. [2] notes that manufacturers and retailers with eco-friendly businesses are more likely to benefit from the increase of consumers' environmental awareness. Subsequently, this proposition has been further examined by Zhang et al. [16]; they focused on the impact of consumer environmental awareness on order quantities and channel coordination. In addition, Basiri and Heydari [17] provided a further exploration of the work of Liu et al. [2], in which they examined how consumer environmental awareness, as an effective parameter, impacts the supply chains' channel coordination by using an analytical model of a two-stage supply chain. In addition, there are some works focused on green technology, green marketing, tax policy, logistics, subsidy policies, etc. to address how to promote the diffusion of GSCM [18-22].

The second stream of research is focused on green-degree-related research on SCM. Zhu and He [10] examined the impact of supply chain structures, green product types, and greenness competition on supply chains' decision variables. The analytical results of Hong and Guo [5] show that product green degree increases as the supply chain cooperation level increases. Ghosh and Shah [23] apply a game-theoretic approach in a two-echelon supply chain with green preferences, which found that a cost-sharing contract can improve greenness and a supply chain's profit. The research of both Madani and Rastibarzoki [6] and Jamali and Rastibarzoki [24] concluded that the higher the green degree is, the higher the competitive advantage of the supply chain and the better the financial performance will be. However, Yu et al. [25] presents a different conclusion that the increase of consumer environmental awareness will incentivize manufacturers to produce more green products with higher green levels, but this does not necessarily lead to higher profits. Chen [26] addressed green product design coordination between traditional and green attributes. The results show that strict environmental criteria are not necessary to improve greenness. This argument is also supported by Fahimnia et al. [27], who noted that not all lean interventions at the tactical supply chain planning level result in green benefits, while a flexible supply chain is the greenest and most efficient alternative. Constructing a competitive mathematical model of government as the leader and two competitive supply chains (green and non-green) as the followers, Madani and Rastibarzoki [6] observed that raising subsidy rates to a certain threshold leads to increases in the market demands, product greenness, and profits of supply chain members and the government, while it leads to decreases in pollution costs for the government. However, most literature does not consider the power differences between the two competitive supply chains. Therefore, in the work of Barari et al. [28], an evolutionary game approach was adopted, which considered vertical and horizontal competition in a duopoly green 
supply chain to explore a synergetic alliance between the environmental and commercial benefits by establishing coordination between the producer and the retailer as well as leveraging the product's greenness. By considering vertical and horizontal competition in a duopoly green supply chain, Chen et al. [29] built the linear demand functions of the duopoly green supply chain and found the players' optimal decisions under channel members' different market power. Furthermore, Yang and Xiao [30] pointed out that government subsidies do not always benefit the green supply chain and the manufacturer depending on channel leadership, and can even result in a first-mover disadvantage for the manufacturer.

The third stream of research is related to production and operation decisions of GSCM. Hsu et al. [31] reports that firms-manufacturers and retailers included-can achieve financial benefits when meeting environmental responsibilities in their production and operations. Liu et al. [32] also suggest that green operation strategy adoption generates many benefits not only to the focal firm, but also to the whole supply chain. Li et al. [1] investigated a competitive dual-channel supply chain, addressed the pricing and greening strategies for the members in both centralized and decentralized cases, and proved that the dual-channel green supply chain does exist. Sarkar and Bhadouriya [33] noted that with only a few manufacturers, green degree is highest in the centralized model, but with a larger number of manufacturers, the green degree is higher in the Stackelberg game scenario than in the centralized model. Agi and Yan [34] argue that a manufacturer-led supply chain is better prepared than a retailer-led supply chain to overcome the fixed cost and to launch a green product. Focusing on green manufacturing, Ma et al. [35] proposed that, in decentralized scenarios, the Stackelberg model is beneficial to manufacturers, while the Bertrand model has an advantage for the retailer. By modeling the environmental responsibility behaviors of both manufacturer and consumers, Yang et al. [36] studied the dual-channel-structure strategy of a green manufacturer. However, they found that although they improve the green degree, dual channels may not be beneficial to environmental protection.

In summary, there are certain limitations in the extant literature with respect to our research focus: (1) Most of the existing literature adopts the Nash game model between supply chains with equal power, and seldom considers the situation that the power status is not equal, that is, "one strong and one weak." It is of great practical significance to study the competition between supply chains with strong and weak relationships, but most of the literature has not conducted in-depth research. (2) Most of the literature only discusses inter-supply-chain price competition, but less considers green degree competition. In practice, with the development of green economy, the green degree competition between supply chains becomes increasingly serious, which becomes a crucial factor for firms' green development, and even that of supply chains. (3) Government subsidies usually take the form of fixed subsidies in much of the literature, while the effect of the green degree of the supply chain on the size of the government subsidy was not considered.

It is these research gaps that motivate us to conduct this research and form the main contributions of this study. To address these research gaps, an analytical model of two competitive two-stage supply chains, which include one manufacturer and one retailer, is established. The manufacturers in each supply chain have two options-producing a green product or non-green product. Two types of competition, - price competition and green degree competition-are considered. Therefore, four decision scenarios, which are derived from the difference in products of the two supply chains, are intended to explore the optimal price and green degree, the dominant strategy of manufacturers, and the influence of inter-supply-chain competition on the supply chain members' profits.

\section{Problem Description and Assumptions}

This section first describes in detail the problem that will be addressed in this study. Then, the notations used throughout the study will be defined. Last, the problem and structure are explained, and mathematical modeling of the problem is performed. 


\subsection{Problem Description}

Consider two horizontal competitive two-stage supply chains for $i(i=1,2)$, which have unequal market positions and bargaining power, i.e., "one strong and one weak" in the Stackelberg game. Without loss of generality, Supply Chain 1 is assumed to be the leader and Supply Chain 2 is the follower in the game. Each supply chain consists of one manufacturer and one retailer; it is assumed that the manufacturer is the leader and the retailer is the follower. The supply chain structure is shown in Figure 1.

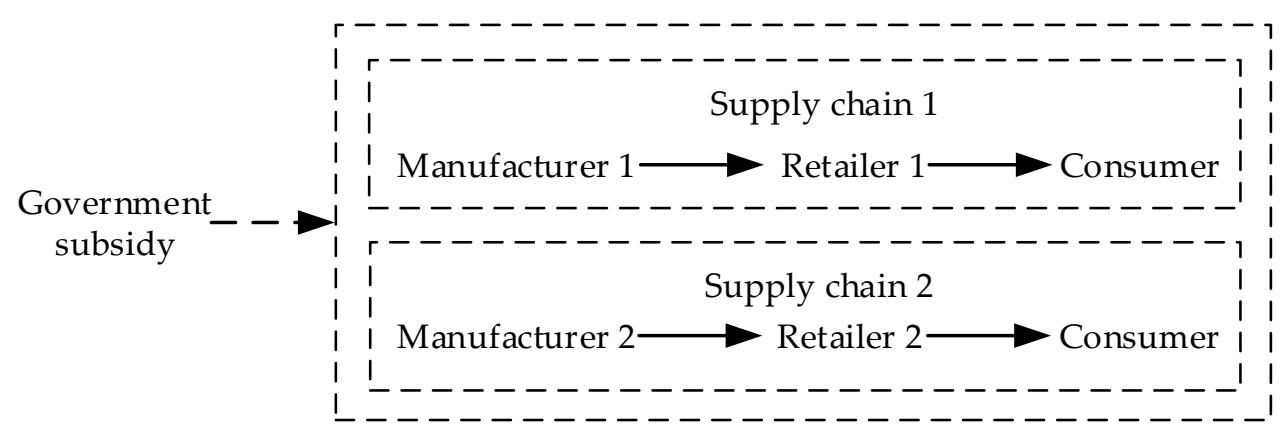

Figure 1. Structure of the supply chains.

The manufacturer in each supply chain has two options-producing a green product $(G)$ or non-green product (C). Accordingly, as an encouragement, the government will subsidize manufacturers who produce green products. In addition, this study considers two types of competition-price competition and green degree competition. Therefore, four decision scenarios, which are derived from the difference in products of the two supply chains, are intended to explore the optimal price and green degree, the dominant strategy of manufacturers, and the influence of inter-supply-chain competition on the supply chain members' profits. The four decision scenarios are shown in Table 1.

Table 1. Four decision scenarios.

\begin{tabular}{|c|c|c|c|}
\hline \multirow{2}{*}{\multicolumn{2}{|c|}{ Supply Chain' Product Strategy }} & \multicolumn{2}{|c|}{ Supply Chain 2's Product Strategy } \\
\hline & & Non-Green Product (C) & Green Product (G) \\
\hline \multirow{2}{*}{$\begin{array}{l}\text { Supply chain 1's product } \\
\text { strategy }\end{array}$} & non-green product $(\mathrm{C})$ & $\mathrm{CC}$ & CG \\
\hline & green product $(\mathrm{G})$ & GC & GG \\
\hline
\end{tabular}

\subsection{Notations}

We define the following variables and notations, which will be used throughout the paper.

$\alpha \quad$ The initial market potential

$\beta \quad$ The coefficient of government subsidy, $\beta \in(0,1)$

$\gamma \quad$ The degree of inter-supply-chain competition, $\gamma \in(0,1)$

$k \quad$ The coefficient of consumer green preference

$\omega_{i} \quad$ The wholesale price of manufacturer $i$ 's product

$p_{i} \quad$ The retail price of retailer $i$

$g_{i} \quad$ The green degree of supply chain $i$

$s_{i} \quad$ The unit subsidy for manufacturer $i$ 's green product

$D_{i} \quad$ The market demand of supply chain $i$

$\pi_{M i}$ The profit function of manufacturer $i$

$\pi_{R i} \quad$ The profit function of retailer $i$

\subsection{Assumptions}

The modeling is based on the following assumptions: 
(1) This study discusses the influence of supply chain green degree on government subsidies. We assume that government subsidies are based on green degree in the form of a unit product subsidy. So, the unit subsidy is $s=\beta g_{i}$, in which $\beta$ is the government's subsidy coefficient for manufacturers producing green products, and $\beta \in(0,1)$. As discussed above, this paper is different from the existing literature in the forms of governmental subsidies that it uses. Most literature uses the form of fixed subsidies, whereas this paper proposes a novel subsidy form based on green degree, which further enriches the study in this field.

(2) As for the demand function, the existing literature has studied both the deterministic demand and the uncertain demand, while the uncertain demand is mainly oriented to the randomness problem [37-39]. The focus of this paper is to consider product decision under the influence of supply chain competition and greenness level. Therefore, this paper sets the demand as deterministic demand. If both supply chains $(i=1,2 ; j=3-i)$ produce non-green products $(\mathrm{CC})$, there is only price competition between the supply chains [40]. The corresponding market demand function is:

$$
D_{i}=\alpha-\frac{1}{1-\gamma} p_{i}+\frac{\gamma}{1-\gamma} p_{j}
$$

When the two competitive supply chains both produce green products (GG), there will be both price competition and greenness competition between the supply chains. In this case, the corresponding market demand function is:

$$
D_{i}=\alpha-\frac{1}{1-\gamma} p_{i}+\frac{\gamma}{1-\gamma} p_{j}+k\left(\frac{1}{1-\gamma} g_{i}-\frac{\gamma}{1-\gamma} g_{j}\right),
$$

where $k$ means that consumers' green preferences will increase market demand for a green product. In addition, there are similar formations that were adopted by Ghosh and Shah [23,41] and Liu and Ji [42] in addressing the sustainability level in sustainable supply chain management. Furthermore, in the intermediate scenarios, if one supply chain produces green products and the other produces non-green products (GC or CG), the corresponding green product market demand function is expressed as:

$$
D_{i}=\alpha-\frac{1}{1-\gamma} p_{i}+\frac{\gamma}{1-\gamma} p_{j}+k g_{i} .
$$

(3) It is assumed that the manufacturer must make an additional investment to produce the green product. Consequently, in this paper, the cost function of producing green products is proposed as a second-order cost function:

$$
C\left(g_{i}\right)=\frac{g_{i}^{2}}{2}
$$

which is a strictly increasing convex function of the supply chain green degree. This assumption is consistent with real production, i.e., the marginal green cost increases more rapidly with the green degree. In addition, it is assumed that the manufacturing cost per unit product is zero; this assumption does not affect the final result comparison. This type of cost function is also considered in other literature [24,43].

Therefore, the profits of the manufacturer producing green products, the manufacturer producing non-green products, and the retailer are shown in Equation (5).

$$
\begin{gathered}
\pi_{M_{i}}^{G}=\left(\omega_{i}+s_{i}\right) D_{i}-\frac{g_{i}^{2}}{2} \\
\pi_{M_{i}}^{C}=\omega_{i} D_{i} \\
\pi_{R_{i}}=\left(p_{i}-\omega_{i}\right) D_{i}
\end{gathered}
$$




\section{Game Model and Solution}

In this section, four decision scenarios (CC, GG, GC, and CG) are considered in the inter-chain game, since both supply chains can choose to produce green products or non-green products.

\subsection{Decision Scenario}

To get a benchmark, we first consider a situation in which both supply chains produce non-green products and have no government subsidy. This is marked as the CC decision scenario. So, there is only price competition between two supply chains. As mentioned above, in this study, a dual Stackelberg game is established, that is, the Stackelberg game approach is employed to handle both inter- and intra-supply-chain competition. More specific, while considering the inter-supply-chain horizontal Stackelberg game, the leading Supply Chain 1 decides the retail price first, and then the follower, Supply Chain 2, makes the optimal response according to the observation. Both of the two competitive supply chains aim to maximize their own profits. In each supply chain, the Stackelberg competition between the manufacturer and the retailer is also established, in which it is assumed that the manufacturer is the leader and the retailer is the follower. So, in each supply chain, the leading manufacturer first sets the wholesale price to maximize its own profit, and then the follower, the retailer, decides the retail price accordingly.

The game equilibrium solution, $\left(\omega_{1}, p_{1}, \omega_{2}, p_{2}\right)$, in the case of the CC decision scenario is solved by backward induction:

$$
\left\{\begin{array}{l}
\omega_{1}^{\mathrm{CC}}=\frac{\alpha\left(\gamma+3 \gamma^{2}-4\right)}{2\left(3 \gamma^{2}-4\right)} \\
p_{1}^{\mathrm{CC}}=\frac{3 \alpha\left(\gamma+3 \gamma^{2}-4\right)}{4\left(3 \gamma^{2}-4\right)} \\
\omega_{2}^{\mathrm{CC}}=\frac{\alpha\left(4 \gamma+15 \gamma^{2}-3 \gamma^{3}-16\right)}{8\left(3 \gamma^{2}-4\right)} \\
p_{2}^{\mathrm{CC}}=\frac{3 \alpha\left(4 \gamma+15 \gamma^{2}-3 \gamma^{3}-16\right)}{16\left(3 \gamma^{2}-4\right)}
\end{array} .\right.
$$

The demands of the two competitive supply chains are obtained as:

$$
\left\{\begin{array}{l}
D_{1}^{C C}=\frac{\alpha(4+3 \gamma)}{16} \\
D_{2}^{C C}=\frac{\alpha\left(3 \gamma^{2}-12 \gamma-16\right)}{16\left(3 \gamma^{2}-4\right)}
\end{array} .\right.
$$

The optimal profits of each member in the two competitive supply chains are derived as follows:

$$
\left\{\begin{array}{l}
\pi_{M_{1}}^{C C}=\frac{\alpha^{2}(\gamma-1)(4+3 \gamma)^{2}}{32\left(3 \gamma^{2}-4\right)} \\
\pi_{R_{1}}^{C C}=\frac{\alpha^{2}(\gamma-1)(4+3 \gamma)^{2}}{64\left(-4+3 \gamma^{2}\right)} \\
\pi_{M_{2}}^{C C}=\frac{\alpha^{2}(1-\gamma)\left(16+12 \gamma-3 \gamma^{2}\right)^{2}}{128\left(4-3 \gamma^{2}\right)^{2}} \\
\pi_{R_{2}}^{C C}=\frac{\alpha^{2}(1-\gamma)\left(16+12 \gamma-3 \gamma^{2}\right)^{2}}{256\left(4-3 \gamma^{2}\right)^{2}}
\end{array}\right.
$$

\subsection{GG Decision Scenario}

In the GG decision scenario, both supply chains produce green products, and the government subsidizes the manufacturers of green products accordingly. In the inter-supply-chain game, the two competitive supply chains both adopt downward decentralized decision-making. The leader, Supply Chain 1, determines the retail price, and the follower, Supply Chain 2, makes the optimal response according to the observation. In the intra-supply-chain game, the leading manufacturer first decides the wholesale price and green degree level to maximize its own profits, and then the follower, the retailer in the supply chain, decides its retail price to maximize its own profits according to the manufacturer's wholesale price and green degree level. 
The game equilibrium solution, $\left(\omega_{1}, p_{1}, g_{1}, \omega_{2}, p_{2}, g_{2}\right)$, in the case of the GG decision scenario is solved by backward induction:

$$
\left\{\begin{array}{l}
\omega_{1}^{G G}=\frac{\alpha\left(A_{1}+\gamma\right)\left[8+\beta(k+\beta) A_{1}-2(k+\beta)^{2}-8 \gamma\right]}{A_{1}\left[16(1-\gamma)+(k+\beta)^{2}\left(A_{1}-4\right)\right]} \\
p_{1}^{G G}=\frac{\alpha\left(A_{1}+\gamma\right)\left[12+\beta(k+\beta) A_{1}-3(k+\beta)^{2}-12 \gamma\right]}{A_{1}\left[16(1-\gamma)+(k+\beta)^{2}\left(A_{1}-4\right)\right]} \\
g_{1}^{G G}=-\frac{\alpha(k+\beta)\left(A_{1}+\gamma\right)}{16(1-\gamma)+(k+\beta)^{2}\left(A_{1}-4\right)} \\
\omega_{2}^{G G}=\frac{\alpha\left(\beta^{2}+k \beta+2 \gamma-2\right) A_{2}}{A_{1}\left[16(1-\gamma)+(k+\beta)^{2}\left(A_{1}-4\right)\right]} \\
p_{2}^{G G}=\frac{\alpha\left(\beta^{2}+k \beta+3 \gamma-3\right) A_{2}}{A_{1}\left[16(1-\gamma)+(k+\beta)^{2}\left(A_{1}-4\right)\right]} \\
g_{2}^{G G}=-\frac{\alpha(k+\beta) A_{2}}{A_{1}\left[16(1-\gamma)+(k+\beta)^{2}\left(A_{1}-4\right)\right]}
\end{array} .\right.
$$

where

$$
\begin{aligned}
A_{1} & =(1+\gamma)(k+\beta)^{2}+3 \gamma^{2}-4 \\
A_{2} & =\left[(k+\beta)^{2}-4\right]^{2}+\left[(k+\beta)^{2}-4\right]\left[2(k+\beta)^{2}+1\right] \gamma \\
& +\left[(k+\beta)^{4}-4(k+\beta)-15\right] \gamma^{2}+3\left[(k+\beta)^{2}+1\right] \gamma^{3}
\end{aligned} .
$$

The demands of the two competitive supply chains are obtained as:

$$
\left\{\begin{array}{l}
D_{1}^{G G}=-\frac{\alpha\left(A_{1}+\gamma\right)}{A_{1}\left[16(1-\gamma)+(k+\beta)^{2}\left(A_{1}-4\right)\right]} \\
D_{2}^{G G}=-\frac{\alpha A_{2}}{A_{1}\left[16(1-\gamma)+(k+\beta)^{2}\left(A_{1}-4\right)\right]}
\end{array} .\right.
$$

The optimal profits of each member in the two competitive supply chains are derived as follows:

$$
\left\{\begin{aligned}
\pi_{M_{1}}^{G G} & =-\frac{\alpha^{2}\left(A_{1}+\gamma\right)^{2}}{2 A_{1}\left[16(1-\gamma)+(k+\beta)^{2}\left(A_{1}-4\right)\right]} \\
\pi_{R_{1}}^{G G} & =\frac{\alpha^{2}\left[(k+\beta)^{2}+4(\gamma-1)\right]\left(A_{1}+\gamma\right)^{2}}{A_{1}\left[16(1-\gamma)+(k+\beta)^{2}\left(A_{1}-4\right)\right]^{2}} \\
\pi_{M_{2}}^{G G} & =-\frac{\alpha^{2}\left[(k+\beta)^{2}+4 \gamma-4\right]\left(A_{2}\right)^{2}}{2\left[16 A_{1}(1-\gamma)+(k+\beta)^{2} A_{1}\left(A_{1}-4\right)\right]^{2}} \\
\pi_{R_{2}}^{G G} & =\frac{\alpha^{2}(1-\gamma)\left(A_{2}\right)^{2}}{\left[16 A_{1}(1-\gamma)+(k+\beta)^{2} A_{1}\left(A_{1}-4\right)\right]^{2}}
\end{aligned}\right.
$$

There is a prerequisite that needs to be met to ensure $g_{i}>0$ and $p_{i}>\omega_{i}>0$, that is $0<\gamma<A_{3}$, where

$$
A_{3}=\frac{1}{6}\left(\sqrt{49+(k+\beta)^{2}\left((k+\beta)^{2}-10\right)}-(k+\beta)^{2}-1\right) .
$$

Proposition 1. In GG decision scenario, in which both supply chains produce green products, the optimal wholesale price is negatively correlated with the degree of inter-supply-chain competition and the government subsidy coefficient, but the optimal supply chain greenness level is positively correlated with them, and the manufacturer's profit is positively correlated with the government subsidy coefficient.

Proposition 1 indicates that, when both supply chains produce green products, as inter-supplychain competition intensifies, the wholesale price will decrease gradually, while the supply chain green degree will increase, which leads to the increase of demand in the two supply chains. As demand increases, manufacturers are more motivated to produce green products, and the supply chain will become greener. Accordingly, with the improvement of the supply chain green degree, the government will increase subsidies to encourage manufacturers to produce more green products, and manufacturers' 
profits increase. Actually, although the increased demand will contribute to the profit growth, the net profit of the manufacturer may increase or decrease due to the additional green cost increase.

\subsection{GC Decision Scenario}

If the leader, Supply Chain 1, produces green products, and the follower, Supply Chain 2, produces non-green products, the government will just subsidize Manufacturer 1 of the green products. Therefore, there are also two Stackelberg dynamic games, i.e., inter- and intra-supply chain.

The game equilibrium solution, $\left(\omega_{1}, p_{1}, g_{1}, \omega_{2}, p_{2}\right)$, in the case of the GC decision scenario is solved by backward induction:

$$
\left\{\begin{array}{l}
\omega_{1}^{G C}=\frac{\alpha(\gamma-1)(4+3 \gamma)\left(8-8 \gamma+\beta B_{2}\right)}{16 k^{2}(\gamma-1)^{2}+B_{1}} \\
p_{1}^{G C}=\frac{\alpha(\gamma-1)(4+3 \gamma)\left(12-12 \gamma+\beta B_{2}\right)}{16 k^{2}(\gamma-1)^{2}+B_{1}} \\
g_{1}^{G C}=\frac{\alpha(1-\gamma)(4+3 \gamma) B_{2}}{16 k^{2}(\gamma-1)^{2}+B_{1}} \\
\omega_{2}^{G C}=\frac{2 \alpha\left[\beta^{2}\left(3 \gamma^{4}-7 \gamma^{2}+4\right)+(\gamma-1)^{2} B_{3}\right]}{16 k^{2}(\gamma-1)^{2}+B_{1}} \\
p_{2}^{G C}=\frac{3 \alpha\left[\beta^{2}\left(3 \gamma^{4}-7 \gamma^{2}+4\right)+(\gamma-1)^{2} B_{3}\right]}{16 k^{2}(\gamma-1)^{2}+B_{1}}
\end{array}\right.
$$

where

$B_{1}=\left(3 \gamma^{2}-4\right)\left[3 \beta^{2} \gamma^{2}+(8 k \beta-16) \gamma+16-8 k \beta-4 \beta^{2}\right]$

$B_{2}=3 \beta \gamma^{2}+4 k \gamma-4(k+\beta)$

$B_{3}=3 \gamma^{2}-\left(4 k^{2}+12\right) \gamma+k \beta\left(8+4 \gamma-3 \gamma^{2}\right)+4 k^{2}-16$.

The demands of the two competitive supply chains are obtained as:

$$
\left\{\begin{array}{l}
D_{1}^{G C}=\frac{\alpha(1-\gamma)(4+3 \gamma)\left(3 \gamma^{2}-4\right)}{1 k^{2}(\gamma-1)^{2}+B_{1}} \\
D_{2}^{G C}=\frac{\alpha\left[(\gamma-1) B_{4}+B_{5}\right]}{16 k^{2}(\gamma-1)^{2}+B_{1}}
\end{array}\right.
$$

where

$$
\begin{aligned}
& B_{4}=3 k \beta \gamma^{2}+\left(4 k^{2}-4 k \beta\right) \gamma-4 k^{2}-8 k \beta \\
& B_{5}=\left(\beta^{2}+1\right)\left(4 \gamma-3 \gamma^{2}-3 \gamma^{3}\right)+4 \beta^{2}-16 .
\end{aligned}
$$

The optimal profits of each member in the two competitive supply chains are derived as follows:

$$
\left\{\begin{array}{rl}
\pi_{M_{1}}^{G C} & =-\frac{\alpha^{2}\left(\gamma+3 \gamma^{2}-4\right)^{2}}{32 k^{2}(\gamma-1)^{2}+2 B_{1}} \\
\pi_{R_{1}}^{G C} & =\frac{4 \alpha^{2}\left(3 \gamma^{2}-4\right)(3 \gamma+4)^{2}(\gamma-1)^{3}}{\left[16 k^{2}(\gamma-1)^{2}+B_{1}\right]^{2}} \\
\pi_{M_{2}}^{G C} & =\frac{2 \alpha^{2}(1-\gamma)\left[(\gamma-1) B_{4}+B_{5}\right]^{2}}{\left[16 k^{2}(\gamma-1)^{2}+B_{1}\right]^{2}} \\
\pi_{R_{2}}^{G C} & =\frac{\alpha^{2}(1-\gamma)\left[(\gamma-1) B_{4}+B_{5}\right]^{2}}{\left[16 k^{2}(\gamma-1)^{2}+B_{1}\right]^{2}}
\end{array} .\right.
$$

Proposition 2. If the leader supply chain produces green products and the follower supply chain produces non-green products, the optimal wholesale price and green degree level are negatively correlated with the inter-supply-chain competition.

Proposition 2 indicates that, in the GC decision scenario, the intensified competition between the two supply chains will result in both manufacturers reducing wholesale prices to capture more market demand. At the same time, the intensification of inter-supply-chain competition will lead to the decline 
of the leader supply chain's green degree level, as well as the further loss of market demand for the green product. Accordingly, Manufacturer 1 will cut down green input to mitigate the loss of market demand. Therefore, the green product strategy is not always beneficial to manufacturers, and the degree of competition between supply chains needs to be fully considered.

\subsection{CG Decision Scenario}

Contrary to the GC decision scenario, if the leader, Supply Chain 1, produces a non-green product, and the follower, Supply Chain 2, produces a green product, the government subsidizes Manufacturer 2 accordingly. Similar to the GC decision scenario, there are also two Stackelberg dynamic games.

The game equilibrium solution, $\left(\omega_{1}, p_{1}, \omega_{2}, p_{2}, g_{2}\right)$, in the case of the CG decision scenario is solved by backward induction:

$$
\left\{\begin{array}{l}
\omega_{1}^{C G}=\frac{\alpha\left[\gamma\left(k^{2}+k \beta-k^{2} \gamma-1\right)+C_{1}\right]}{2 C_{1}} \\
p_{1}^{C G}=\frac{3 \alpha\left[\gamma\left(k^{2}+k \beta-k^{2} \gamma-1\right)+C_{1}\right]}{4 C_{1}} \\
\omega_{2}^{C G}=\frac{\alpha[\beta(k+\beta-k \gamma)+2(\gamma-1)]\left(C_{2}+C_{3}\right)}{4 C_{1}\left[4(\gamma-1)+(k+\beta-k \gamma)^{2}\right]} \\
p_{2}^{C G}=\frac{\alpha[\beta(k+\beta-k \gamma)+3(\gamma-1)]\left(C_{2}+C_{3}\right)}{4 C_{1}\left[4(\gamma-1)+(k+\beta-k \gamma)^{2}\right]} \\
g_{2}^{C G}=\frac{\alpha(k \gamma-k-\beta)\left(C_{2}+C_{3}\right)}{4 C_{1}\left[4(\gamma-1)+(k+\beta-k \gamma)^{2}\right]}
\end{array}\right.
$$

where

$C_{1}=4-(k+\beta)^{2}+\left(k^{2}-\beta^{2}\right) \gamma+(k \beta-3) \gamma^{2}$
$C_{2}=\beta^{2}(\gamma-4)(\gamma+1)-k^{2}(\gamma-1)^{2}(3 \gamma+4)$
$C_{3}=k \beta(1-\gamma)\left(\gamma^{2}-6 \gamma-8\right)+3 \gamma^{3}-15 \gamma^{2}-4 \gamma+16$.

The demands of the two competitive supply chains are obtained as:

$$
\left\{\begin{array}{l}
D_{1}^{C G}=\frac{\alpha\left[\gamma\left(k^{2}+k \beta-k^{2} \gamma-1\right)+C_{1}\right]}{16(\gamma-1)+4(k+\beta-k \gamma)^{2}} \\
D_{2}^{C G}=\frac{3 \alpha(\gamma+1)}{4 C_{1}}+\frac{\alpha(\gamma-1)}{16(\gamma-1)+4(k+\beta-k \gamma)^{2}}
\end{array} .\right.
$$

The optimal profits of each member in the two competitive supply chains are derived as follows:

$$
\left\{\begin{aligned}
\pi_{M_{1}}^{C G} & =\frac{\alpha^{2}\left[\gamma\left(k^{2}+k \beta-k^{2} \gamma-1\right)+C_{1}\right]^{2}}{8 C_{1}\left[4(\gamma-1)+(k+\beta-k \gamma)^{2}\right]} \\
\pi_{R_{1}}^{C G} & =\frac{\alpha^{2}\left[\gamma\left(k^{2}+k \beta-k^{2} \gamma-1\right)+C_{1}\right]^{2}}{16 C_{1}\left[4(\gamma-1)+(k+\beta-k \gamma)^{2}\right]} \\
\pi_{M_{2}}^{C G} & =-\frac{\alpha^{2}\left(C_{2}+C_{3}\right)^{2}}{32\left[4(\gamma-1)+(k+\beta-k \gamma)^{2}\right]\left(C_{1}\right)^{2}} \\
\pi_{R_{2}}^{C G} & =\frac{\alpha^{2}(1-\gamma)\left(C_{2}+C_{3}\right)^{2}}{16\left[4 C_{1}(\gamma-1)+(k+\beta-k \gamma)^{2} C_{1}\right]^{2}}
\end{aligned}\right.
$$

Proposition 3. If the leader supply chain produces non-green products and the follower supply chain produces green products, the optimal wholesale price is negatively correlated with the inter-supply-chain competition, while the green degree level is positively correlated with the inter-supply-chain competition.

Proposition 3 indicates that, in the CG decision scenario, the intensified competition between the two supply chains will also result in a downward trend in wholesale prices. However, it is different from Proposition 2 in that the intensification of the competition between supply chains will lead to the increase of the follower supply chain's green degree level with the corresponding increase of green product market demand. Compared with the non-green product supply chain, inter-supply-chain competition further increases the market demand of the follower supply chain. The results show that 
the inter-supply-chain competition has a positive effect on the follower supply chain. Accordingly, Manufacturer 2 will add green input to expand its market share to enhance the follower's competition. Together with Proposition 2, it can be seen that the competition between supply chains has different effects on the green degree of different supply chains.

\section{Comparison and Analyses}

Based on the four aforementioned decision scenarios, a critical comparison analysis will be made to discuss some key parameters and propose corresponding propositions.

\subsection{Comparison between the CC and GC Scenarios}

For Supply Chain 1, by comparing its wholesale price, when the condition $\gamma \in\left(0, \frac{2\left(k-\sqrt{k^{2}-3 k \beta+3 \beta^{2}}\right)}{3 \beta}\right)$ is satisfied, then the following conclusion holds: $\omega_{1}^{G C}>\omega_{1}^{C C}$; and when $\gamma \in\left(\frac{2\left(k-\sqrt{k^{2}-3 k \beta+3 \beta^{2}}\right)}{3 \beta}, A_{3}\right)$, then $\omega_{1}^{G C}<\omega_{1}^{C C}$. For the market demands of supply chain, there always exists $D_{1}^{G C}>D_{1}^{C C}$. In particular, when the follower supply chain chooses to produce non-green products, and if the competition between supply chains is not fierce, the leader supply chain's green product strategy is beneficial. However, if the competition between supply chains is fierce to a certain degree, the manufacturers will choose to produce non-green products, which enables the manufacturers to obtain higher wholesale prices but lower demand. This finding indicates that the green product strategy is not always beneficial to manufacturers, and the degree of competition between supply chains needs to be fully considered. This finding further proves Proposition 2.

For Supply Chain 2, we find that $\omega_{2}^{G C}>\omega_{2}^{C C}$ and $D_{2}^{G C}>D_{2}^{C C}$ through comparison. This means that both the wholesale price and the demand in the follower supply chain will increase. This shows that the green production behavior of the leader supply chain has a "positive spillover effect" on the follower supply chain. In this case, the follower supply chain can still benefit Manufacturer 2 by choosing to produce non-green products.

\subsection{Comparison between the CC and CG Scenarios}

For Supply Chain 2, we find that $\omega_{2}^{C G}>\omega_{2}^{C C}$ and $D_{2}^{C G}>D_{2}^{C C}$. In other words, when the leader, Supply Chain 1, produces non-green products, the follower's (Supply Chain 2) wholesale price and market demand for green products are higher than in the case of non-green products. Although the wholesale price of green products is higher due to the competition between supply chains, the demand does not decrease, that is, the demand for green products is always higher than the demand for non-green products. Furthermore, Proposition 3 shows that the green degree is positively correlated with the competition between supply chains. In the CG decision scenario, the intensification of the competition improved the green degree of the follower supply chain. Consumers with a green preference are willing to buy green products and pay the premium. So, although the price of green products is higher than that of non-green products, the demand does not decrease. This finding will contribute to encouraging firms to implement green production plans.

For Supply Chain 1, we find that $\omega_{1}^{C G}>\omega_{1}^{C C}$ and $D_{1}^{C G}>D_{1}^{C C}$. In other words, when the leader, Supply Chain 1, produces non-green products, and the follower, Supply Chain 2, produces green products, both the wholesale price and market demand for non-green products increased. This shows that the green production behavior of the follower, Supply Chain 2, has a "positive spillover effect" on the leader, Supply Chain 1. In this case, the leader, Supply Chain 1, can still benefit from Manufacturer 1 by choosing to produce non-green products.

Proposition 4. To sum up, the demands in the GC and CG decision scenarios are higher than in the CC scenario, that is, if one supply chain produces green products and the other produces non-green products is better than if both supply chains produce non-green goods. The coexistence of two products is beneficial to the two competitive 
supply chains, and a win-win situation can be achieved. Meanwhile, it also proves that green products have a significant advantage compared with non-green products. Even though the price is higher, the demand will not decrease.

\subsection{Comparison between the GC, CG, and GG Scenarios}

Because the calculation in the GG decision scenario is too complex, it is impossible to directly discuss the parameters as above. In this regard, a numerical simulation experiment method is introduced for this comparison. According to the research in the literature [23,41,42], we set the parameter values $\alpha=10, \beta=0.1$, and $k=0.4$ for the numerical example to observe the influence of competition between supply chains on the wholesale prices.

The influence of inter-supply-chain competition on the wholesale price under different decision scenarios is shown in Figure 2. As shown in Figure 2, the wholesale price is negatively correlated with inter-supply-chain competition. A point to be noticed is that in Figure 2, the values of wholesale price under the GC and CG decision scenarios exhibit a trend of convergence with the increase of inter-supply-chain competition.

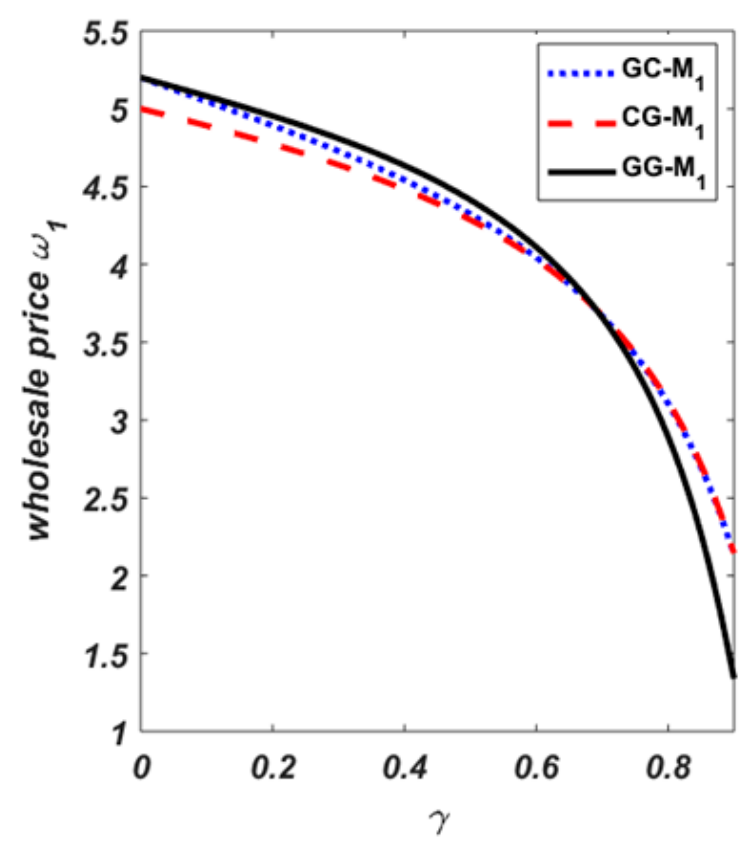

(a)

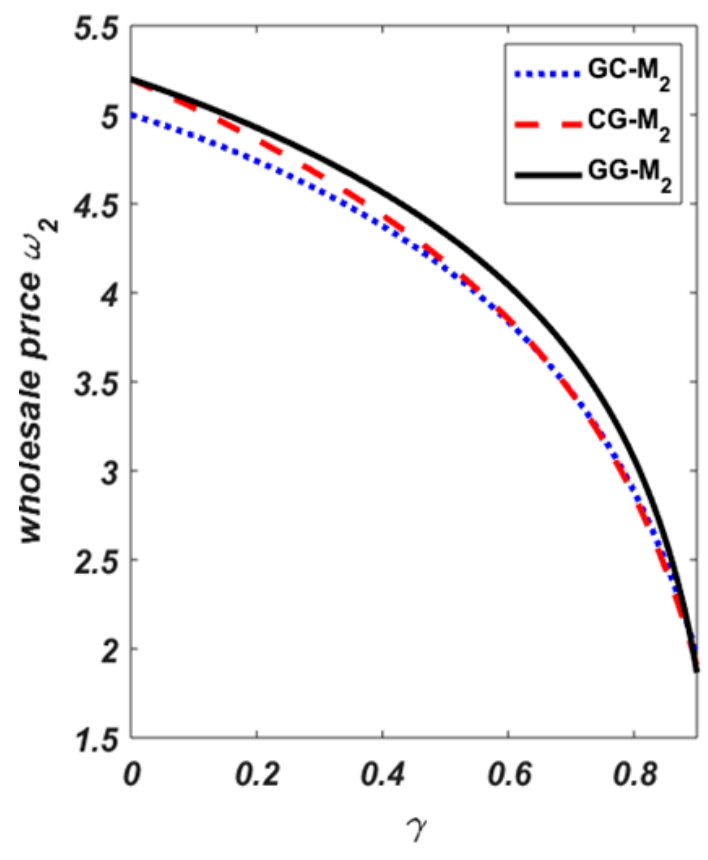

(b)

Figure 2. Influence of inter-supply-chain competition on wholesale price under different decision scenarios.

For wholesale price $\omega_{2}$, the following conclusions always holds: $\omega_{2}^{G G}>\omega_{2}^{G C}$ and $\omega_{2}^{G G}>\omega_{2}^{\mathrm{CG}}$. This shows that no matter how the degree of competition between chains changes, Manufacturer 2 can obtain the highest wholesale price to make profits under the GG decision scenario, and the follower supply chain chooses to produce green products as the dominant strategy. Nevertheless, for Manufacturer 1 , the changes of wholesale price $\omega_{1}$ depend on the degree of competition between the chains. When the competition is not fierce, the wholesale price $\omega_{1}^{G G}$ is the highest under the GG decision scenario. However, when the competition is fierce, $\omega_{1}^{G G}$ is the lowest. This finding indicates that it is beneficial when both supply chains proactively moderate the competition. As the leader, Supply Chain 1 can lower the competition by reducing the greening initiatives so as to keep the wholesale price at a high level, which make benefits for both parties. Moreover, for the two competitive supply chains, it is the optimal decision for both of them to produce green products (GG) when the 
inter-supply-chain competition is weak. However, when it is fierce, the optimal decision for the leader supply chain is to produce non-green products, and for the follower supply chain, it is to produce green products (CG), which enables the manufacturers in the two supply chains to obtain the highest wholesale prices.

\section{Numerical Analysis}

In this section, following the above discussion, a numerical example is proposed to further analyze the influence of supply chain competition on the profits of each member in each scenario. According to the research in the literature [23,41,42], some parameter values are set, like above, as $\alpha=10, \beta=0.1$, and $k=0.4$. The inter-supply-chain coefficient $\gamma$ will vary from 0 to 0.9 , and observations will be made on how the changes affect the profits.

\subsection{The Influence of Competition on Manufacturers' Profits}

According to Figure 3, with the increase of competition between the two supply chains, manufacturers' profits in the different decision scenarios show a trend of increasing first and then decreasing. The reason is that, as competition intensifies, manufacturers gain more demand by lowering wholesale prices and increasing the greenness of their products. Therefore, manufacturers' profits increase accordingly. However, when the competition is very fierce, the wholesale price will continue to decrease, which means that the profit resulting from the increased demand is unable to make up for the green input cost of the manufacturers, so the overall profit of the manufacturers decreases.

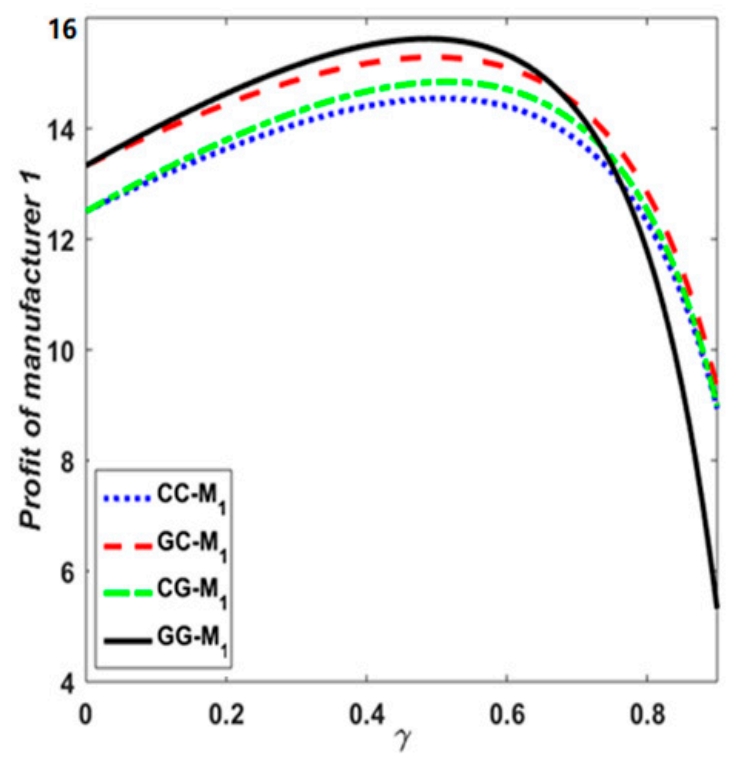

(a)

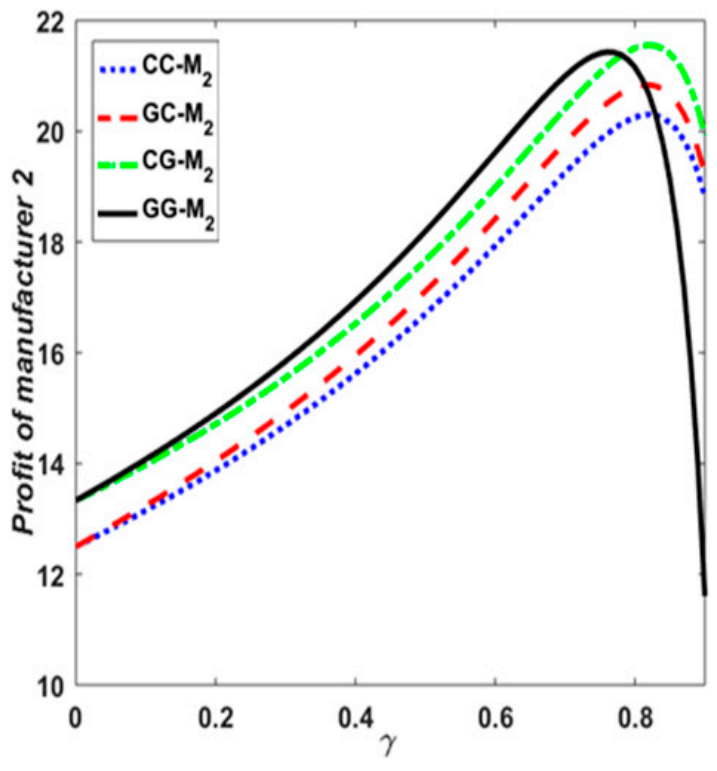

(b)

Figure 3. Influence of competition between supply chains on manufacturers' profits.

Specifically, for Manufacturer 1, the conclusion $\pi_{M_{1}}^{G C}>\pi_{M_{1}}^{C C}$ always holds. It shows that no matter how the degree of competition changes, if the follower, Supply Chain 2, chooses to produce non-green products, Manufacturer 1 can always capture more profit by choosing to produce green products rather than non-green products. Furthermore, when $\gamma \in(0,0.73)$, then $\pi_{M_{1}}^{G G}>\pi_{M_{1}}^{C G}$; however, when $\gamma \in(0.73,0.9)$, then $\pi_{M_{1}}^{G G}<\pi_{M_{1}}^{C G}$. This indicates that if the competition is not fierce and the follower, Supply Chain 2, chooses to produce green products, Manufacturer 1 will adopt a green product strategy to get more profits than from the non-green products, i.e., green products are the dominant strategy. On the contrary, if the competition is very fierce, Manufacturer 1 will make more profit by producing non-green products, i.e., non-green products are the dominant strategy. 
For Manufacturer 2, the conclusion $\pi_{M_{2}}^{C G}>\pi_{M_{2}}^{C C}$ always holds. It shows that no matter how the degree of competition changes, if the leader, Supply Chain 1, chooses to produce non-green products, Manufacturer 2 will obtain more profits by choosing green products rather than non-green products. Furthermore, when $\gamma \in(0,0.81)$, then $\pi_{M_{2}}^{G G}>\pi_{M_{2}}^{G C}$; however, when $\gamma \in(0.81,0.9)$, then $\pi_{M_{2}}^{G G}<\pi_{M_{2}}^{G C}$. This indicates that if the competition is not fierce, and the leader, Supply Chain 1, chooses to produce green products, Manufacturer 2 will obtain more profits by choosing to produce green products rather than non-green products. On the contrary, if the competition is very fierce, Manufacturer 2 will maximize its profits by producing non-green products.

Proposition 5. To sum up, if one manufacturer chooses to produce non-green products, it is beneficial for the other to choose to produce green products. Nevertheless, if it chooses to produce green products, when the competition is not fierce, the GG decision will always be the dominant strategy, which can maximize the profits of both sides. When the competition is very fierce, the manufacturer's dominant strategy is the GC or CG decision, that is, one supply chain chooses green products and the other chooses non-green products.

Next, in order to more clearly describe the influence of inter-supply-chain competition on the profits of each manufacturer under each decision scenario, we set the parameter $\gamma$ to vary from 0 to 0.9 ; thus, Table 2 is obtained.

Table 2. Influence of inter-supply-chain competition on manufacturers' profits under the four decision scenarios.

\begin{tabular}{ccccccccc}
\hline \multirow{2}{*}{$\gamma$} & \multicolumn{3}{c}{ Profit of Manufacturer 1 } & \multicolumn{3}{c}{ Profit of Manufacturer 2 } \\
\cline { 2 - 9 } & CC & GC & CG & GG & CC & GC & CG & GG \\
\hline 0.1 & 13.10 & 13.92 & 13.18 & 14.02 & 13.15 & 13.24 & 13.98 & 14.08 \\
0.2 & 13.63 & 14.44 & 13.79 & 14.63 & 13.87 & 14.05 & 14.71 & 14.90 \\
0.3 & 14.08 & 14.87 & 14.30 & 15.14 & 14.69 & 14.94 & 15.55 & 15.85 \\
0.4 & 14.40 & 15.18 & 14.67 & 15.50 & 15.60 & 15.95 & 16.53 & 16.93 \\
0.5 & 14.54 & 15.29 & 14.84 & 15.62 & 15.70 & 17.11 & 17.67 & 18.19 \\
0.6 & 14.40 & 15.10 & 14.71 & 15.33 & 17.93 & 18.42 & 18.99 & 19.62 \\
0.7 & 13.79 & 14.43 & 14.08 & 14.32 & 19.25 & 19.79 & 20.41 & 21.00 \\
0.8 & 12.31 & 12.85 & 12.54 & 11.79 & 20.25 & 20.80 & 21.50 & 21.15 \\
0.9 & 8.54 & 9.31 & 8.99 & 5.32 & 18.82 & 19.22 & 19.93 & 11.60 \\
\hline
\end{tabular}

As can be seen from Table 2, no matter how the degree of competition changes, the conclusions, $\pi_{M_{1}}^{C C}<\pi_{M_{2}}^{C C}, \pi_{M_{1}}^{C G}<\pi_{M_{2}}^{C G}$, and $\pi_{M_{1}}^{G G}<\pi_{M_{2}}^{G G}$, always hold in the CC, CG, and GG decision scenarios, respectively. This means that, in the CC, ${ }^{\prime} G$, and GG decision scenarios, Manufacturer 2's profits are always higher than those of Manufacturer 1. This is an important finding of this paper, which differs from the conventional knowledge. This finding is of great theoretical significance in addressing the competition scenario of unequal powers in GSCM. However, in the GC decision scenario, when $\gamma \in(0,0.2)$, then $\pi_{M_{1}}^{G C}>\pi_{M_{2}}^{G C}$; otherwise, if $\gamma \in(0.2,0.9)$, then $\pi_{M_{1}}^{G C}<\pi_{M_{2}}^{G C}$. This indicates that if the leader, Supply Chain 1, chooses to produce green products, and the follower, Supply Chain 2, chooses to produce non-green products, weak market competition will benefit Manufacturer 1, while Manufacturer 2 will benefit more from strong market competition. In combination with Proposition 2, the optimal wholesale price and green degree are negatively correlated with inter-supply-chain competition. The intensification of competition leads to the decrease of the green degree of the leader supply chain and the decrease of market demand for green products. Moreover, the decrease of supply chain green degree reduces the government subsidies for green products, so the profit of Manufacturer 1 decreases.

\subsection{The Influence of Competition on Retailers' Profits}

As a follower in the supply chain network, the retailer is strongly influenced by the manufacturer's strategy. As can be seen from Figure 4, with the intensification of the competition between supply 
chains, retailers' profits under different decision scenarios show a trend of increasing first and then decreasing, and $\pi_{R_{i}}^{G G}>\pi_{R_{i}}^{C C}$ is always true. This indicates that for the retailer, no matter how the competition degree changes, choosing green products is always the dominant strategy to maximize its own profits. Nevertheless, according to Proposition 5, if one supply chain chooses to produce green products when the competition is not fierce, the other's dominant strategy is also to produce green products, which will maximize the profits of both sides. When the competition is very fierce, the other manufacturer's dominant strategy is to produce non-green products, i.e., the GC or CG strategy. Therefore, the optimal strategies of manufacturers and retailers will be different. For the retailer, its profit will be affected by the manufacturers' strategies. In addition, according to Figure 4, Retailer 1's profit changes more gently than that of Retailer 2, that is, the range of increase or decrease of the retailer's profit caused by the change of competition degree per unit is smaller. This indicates that Retailer 2 is more sensitive to changes in inter-supply-chain competition. The reason is that the follower, Supply Chain 2, is in a subordinate position in the competition. Retailer 2 must make corresponding decisions based on the strategies of Manufacturer 2 and the leader, Supply Chain 1, to maximize its own profit.

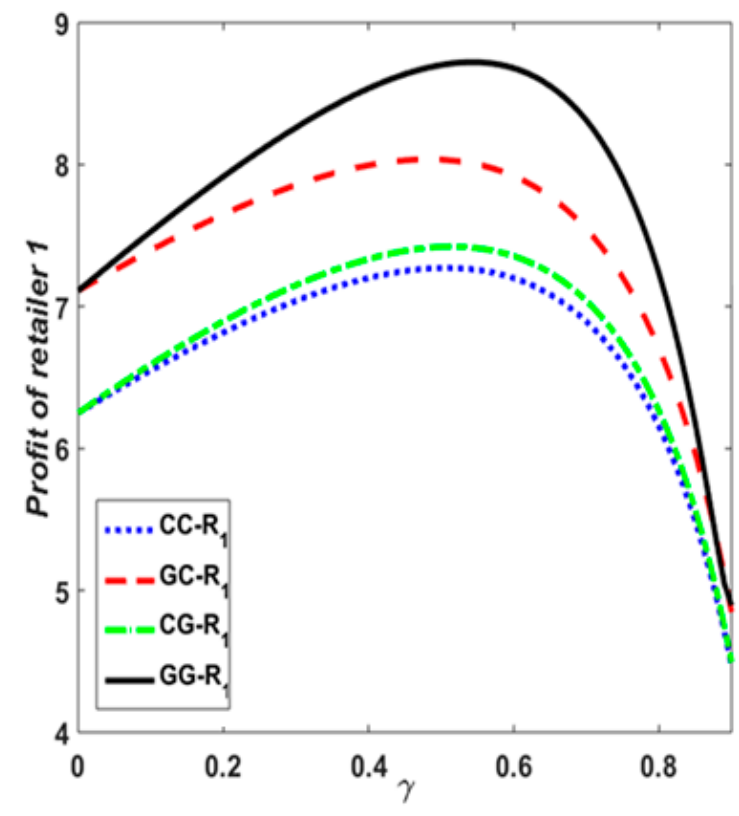

(a)

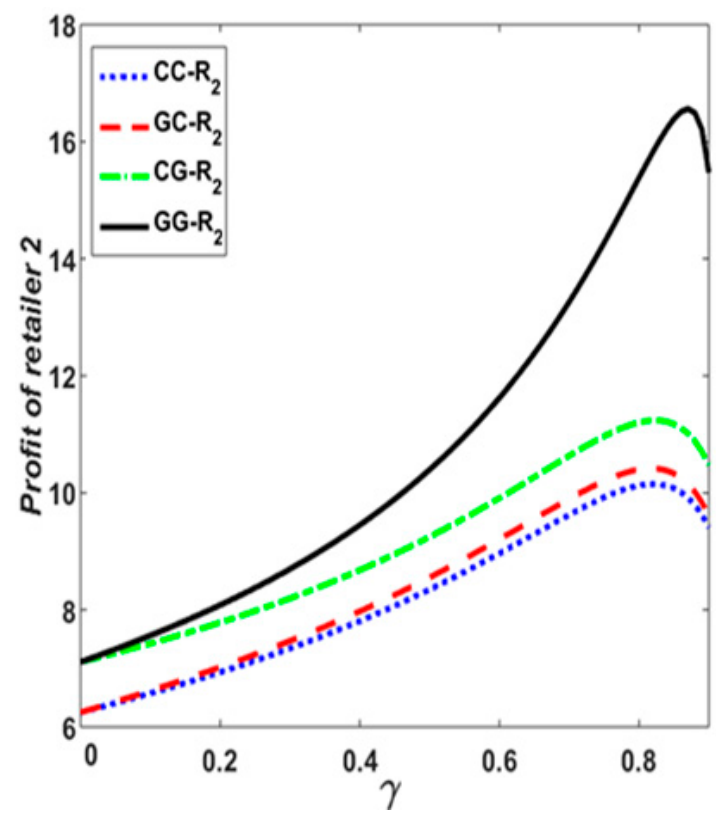

(b)

Figure 4. Influence of competition between supply chains on retailers' profits.

Similarly, in order to more clearly describe the influence of inter-supply-chain competition on the profits of each retailer under each decision scenario, we set the parameter $\gamma$ to vary from 0 to 0.9 ; thus, Table 3 is obtained.

As can be seen from Table 3, no matter how the degree of competition changes, the conclusions, $\pi_{R_{1}}^{C C}<\pi_{R_{2}}^{C C}, \pi_{R_{1}}^{C G}<\pi_{R_{2}}^{C G}$, and $\pi_{R_{1}}^{G G}<\pi_{R_{2}}^{G G}$, always hold in the CC, CG and GG decision scenarios, respectively. This means that, in the CC, CG, and GG decision scenarios, Retailer 2's profits are always higher than those of Retailer 1. This finding is also different from the conventional knowledge. This finding is of great theoretical significance in addressing the competition scenario of unequal powers in GSCM. However, in the GC decision scenario, when $\gamma \in(0,0.5)$, then $\pi_{R_{1}}^{G C}>\pi_{R_{2}}^{G C}$; otherwise, if $\gamma \in(0.5,0.9)$, then $\pi_{R_{1}}^{G C}<\pi_{R_{2}}^{G C}$. This indicates that if the leader, Supply Chain 1 , chooses to produce 
green products, and the follower, Supply Chain 2, chooses to produce non-green products, weak market competition will benefit Retailer 1, while Retailer 2 will benefit more from strong market competition.

Table 3. Influence of inter-supply-chain competition on retailers' profits under the four decision scenarios.

\begin{tabular}{ccccccccc}
\hline \multirow{2}{*}{$\gamma$} & \multicolumn{3}{c}{ Profit of Retailer 1 } & \multicolumn{3}{c}{ Profit of Retailer 2 } \\
\cline { 2 - 8 } & CC & GC & CG & GG & CC & GC & CG & GG \\
\hline 0.1 & 6.55 & 7.40 & 6.59 & 7.53 & 6.58 & 6.62 & 7.43 & 7.56 \\
0.2 & 6.82 & 7.65 & 6.90 & 7.92 & 6.94 & 7.02 & 7.78 & 8.08 \\
0.3 & 7.04 & 7.86 & 7.15 & 8.26 & 7.34 & 7.47 & 8.20 & 8.70 \\
0.4 & 7.20 & 8.00 & 7.34 & 8.54 & 7.81 & 7.98 & 8.68 & 9.45 \\
0.5 & 7.27 & 8.03 & 7.42 & 8.70 & 8.35 & 8.56 & 9.25 & 10.40 \\
0.6 & 7.20 & 7.92 & 7.36 & 8.68 & 8.97 & 9.21 & 9.91 & 11.63 \\
0.7 & 6.89 & 7.55 & 7.04 & 8.31 & 9.63 & 9.90 & 10.63 & 13.26 \\
0.8 & 6.15 & 6.70 & 6.27 & 7.23 & 10.13 & 10.40 & 11.20 & 15.38 \\
0.9 & 4.47 & 4.85 & 4.49 & 4.89 & 9.41 & 9.61 & 10.48 & 15.47 \\
\hline
\end{tabular}

\section{Discussion and Conclusions}

This paper studies green supply chain decision-making under the influence of competition between supply chains by building a dual Stackelberg game model of intra- and inter-supply-chain competition with full consideration of the two competitive supply chains. The conclusions are as follows:

(1) Inter-supply-chain competition will have an impact on wholesale prices. The competition is negatively correlated with wholesale price, which suggests that the two supply chains should adopt proactive strategies to mitigate inter-supply-chain competition. As the leader, Supply Chain 1 can reduce the degree of competition by reducing green input so as to keep the wholesale price at a high level and benefit both sides. Specifically, for manufacturers, green products are not always the dominant strategies, and the degree of competition between supply chains should be fully considered. When the competition is weak, the green product is the dominant strategy. Otherwise, the non-green product is the dominant strategy.

(2) Inter-supply-chain competition will have different effects on supply chain green degree, i.e., the two supply chains' green degrees are positively correlated with the competition between supply chains in the GG decision scenario. There is a negative correlation between the green degree and the competition in the GC decision scenario. However, in the CG decision scenario, the green degree of the follower supply chain is positively correlated with the competition.

(3) Inter-supply-chain competition will have an impact on the decision-making of the two supply chains: When the competition is not fierce, the GG decision will always be the dominant strategy to maximize the profits of both sides; otherwise, if the competition between chains is very fierce, the dominant strategy is the GC or CG decision, that is, one supply chain chooses green products and the other supply chain chooses non-green products.

(4) This study finds that no matter how the degree of competition between chains changes, the profit of the follower supply chain in the CC, CG, and GG decision scenarios is higher than that of the leader supply chain. The profit in the GC decision scenario needs to consider the situation of the competition between supply chains. Weak competition is beneficial to the leader supply chain, while increased competition is good for the follower supply chain. The strongest and largest enterprises may not survive, while the most adaptable enterprises will survive. Therefore, enterprises should make decisions to optimize their production strategies dynamically and purposefully from the perspective of supply chains in view of external environmental changes and market fluctuations. This is an important finding of this paper, which extends the competitive decision theory in GSCM and has theoretical and practical significance for decision-makers in different competitive positions in the process of unequal power competition between supply chains. 
With the models and findings explored in this paper, our research can offer insightful recommendations for industries. For future research directions, we would like to further explore this topic from the following perspectives. First, the influence of information distortion caused by asymmetric information between supply chains on decision-making in GSCM could be considered. Second, considering intra-supply-chain competition, a retailer-dominant scenario in which the manufacturer is the follower would enrich this study. Third, empirical research based on field investigation in a wider contextual setting is strongly recommended.

Author Contributions: J.W. and J.C. designed the research and game model. J.W., J.C., and Y.W. discussed the optimization method. J.C. and Y.W. designed the numerical experiment. All authors have read and agreed to the published version of the manuscript.

Funding: This research was funded by Postgraduate Education Innovation Project of Shanxi Province in 2020 (Grant No. 2020SY023), Youth Research Fund Project of Shanxi University of Finance and Economics (Grant No. QN-202002), and the Philosophy and Social Science Project of Colleges and Universities in Shanxi Province in 2020 (Grant No. 2020W071).

Acknowledgments: Thanks to all the persons in the research group; they gave us many valuable suggestions in the process of our writing.

Conflicts of Interest: The authors declare no conflict of interest.

\section{References}

1. Li, B.; Zhu, M.; Jiang, Y.; Li, Z. Pricing policies of a competitive dual-channel green supply chain. J. Clean. Prod. 2016, 112, 2029-2042. [CrossRef]

2. Liu, Z.; Anderson, T.; Cruz, J.M. Consumer environmental awareness and competition in two-stage supply chains. Eur. J. Oper. Res. 2012, 218, 602-613. [CrossRef]

3. Wang, F.; Lai, X.; Shi, N. A multi-objective optimization for green supply chain network design. Decis. Support Syst. 2011, 51, 262-269. [CrossRef]

4. Green, K.W.; Zelbst, P.J.; Meacham, J.; Bhadauria, V.S. Green supply chain management practices: Impact on performance. Supply Chain. Manag. 2012, 17, 290-305. [CrossRef]

5. Hong, Z.; Guo, X. Green product supply chain contracts considering environmental responsibilities. Omega 2019, 83, 155-166. [CrossRef]

6. Madani, S.R.; Rastibarzoki, M. Sustainable supply chain management with pricing, greening and governmental tariffs determining strategies: A game-theoretic approach. Comput. Ind. Eng. 2017, 105, 287-298. [CrossRef]

7. Dangelico, R.M.; Pujari, D. Mainstreaming green product innovation: Why and how companies integrate environmental sustainability. J. Bus. Ethics 2010, 95, 471-486. [CrossRef]

8. Tang, C.S.; Zhou, S.X. Research advances in environmentally and socially sustainable operations. Eur. J. Oper. Res. 2012, 223, 585-594. [CrossRef]

9. Srivastava, S.K. Green supply-chain management: A state-of-the-art literature review. Int. J. Manag. Rev. 2007, 9, 53-80. [CrossRef]

10. Zhu, W.; He, Y. Green product design in supply chains under competition. Eur. J. Oper. Res. 2017, 258, 165-180. [CrossRef]

11. Fahimnia, B.; Sarkis, J.; Davarzani, H. Green supply chain management: A review and bibliometric analysis. Int. J. Prod. Econ. 2015, 162, 101-114. [CrossRef]

12. Ahi, P.; Searcy, C. A comparative literature analysis of definitions for green and sustainable supply chain management. J. Clean. Prod. 2013, 52, 329-341. [CrossRef]

13. Zhu, Q.; Sarkis, J.; Lai, K.H. Examining the effects of green supply chain management practices and their mediations on performance improvements. Int. J. Prod. Res. 2012, 50, 1377-1394. [CrossRef]

14. Hervani, A.A.; Helms, M.M.; Sarkis, J. Performance measurement for green supply chain management. Benchmarking 2005, 12, 330-353. [CrossRef]

15. Rao, P.; Holt, D. Do green supply chains lead to competitiveness and economic performance. Int. J. Oper. Prod. Manag. 2005, 25, 898-916. [CrossRef]

16. Zhang, L.; Wang, J.; You, J. Consumer environmental awareness and channel coordination with two substitutable products. Eur. J. Oper. Res. 2015, 241, 63-73. [CrossRef] 
17. Basiri, Z.; Heydari, J. A mathematical model for green supply chain coordination with substitutable products. J. Clean. Prod. 2017, 145, 232-249. [CrossRef]

18. Chen, Y.S. The driver of green innovation and green image-green core competence. J. Bus. Ethics 2008, 81, 531-543. [CrossRef]

19. Wu, G. The influence of green supply chain integration and environmental uncertainty on green innovation in Taiwan's IT industry. Supply Chain Manag. 2013, 18, 539-552. [CrossRef]

20. Vachon, S. Green supply chain practices and the selection of environmental technologies. Int. J. Prod. Res. 2007, 45, 4357-4379. [CrossRef]

21. Sheu, J.B.; Chen, Y.J. Impact of government financial intervention on competition among green supply chains. Int. J. Prod. Econ. 2012, 138, 201-213. [CrossRef]

22. Rahbar, E.; Wahid, N.A. Investigation of green marketing tools' effect on consumers' purchase behavior. Bus. Strategy Ser. 2011, 12, 73-83. [CrossRef]

23. Ghosh, D.; Shah, J. Supply chain analysis under green sensitive consumer demand and cost sharing contract. Int. J. Prod. Econ. 2015, 164, 319-329. [CrossRef]

24. Jamali, M.; Rastibarzoki, M. A game theoretic approach for green and non-green product pricing in chain-to-chain competitive sustainable and regular dual-channel supply chains. J. Clean. Prod. 2018, 170, 1029-1043. [CrossRef]

25. Yu, Y.; Han, X.; Hu, G. Optimal production for manufacturers considering consumer environmental awareness and green subsidies. Int. J. Prod. Econ. 2016, 182, 397-408. [CrossRef]

26. Chen, C. Design for the environment: A quality-based model for green product development. Manag. Sci. 2001, 47, 250-263. [CrossRef]

27. Fahimnia, B.; Sarkis, J.; Eshragh, A. A tradeoff model for green supply chain planning: A leanness-versusgreenness analysis. Omega 2015, 54, 173-190. [CrossRef]

28. Barari, S.; Agarwal, G.; Zhang, W.C.; Mahanty, B.; Tiwari, M.K. A decision framework for the analysis of green supply chain contracts: An evolutionary game approach. Expert Syst. Appl. 2012, 39, 2965-2976. [CrossRef]

29. Chen, S.; Wang, X.; Ni, L.; Wu, Y. Pricing policies in green supply chains with vertical and horizontal competition. Sustainability 2017, 9, 2359. [CrossRef]

30. Yang, D.; Xiao, T. Pricing and green level decisions of a green supply chain with governmental interventions under fuzzy uncertainties. J. Clean. Prod. 2017, 149, 1174-1187. [CrossRef]

31. Hsu, C.; Tan, K.C.; Zailani, S.H.; Jayaraman, V. Supply chain drivers that foster the development of green initiatives in an emerging economy. Int. J. Oper. Prod. Manag. 2013, 33, 656-688. [CrossRef]

32. Liu, Y.; Zhang, Y.; Batista, L.; Rong, K. Green operations: What's the role of supply chain flexibility? Int. J. Prod. Econ. 2019, 214, 30-43. [CrossRef]

33. Sarkar, S.; Bhadouriya, A. Manufacturer competition and collusion in a two-echelon green supply chain with production trade-off between non-green and green quality. J. Clean. Prod. 2020, 253. in press. [CrossRef]

34. Agi, M.A.; Yan, X. Greening products in a supply chain under market segmentation and different channel power structures. Int. J. Prod. Econ. 2020, 223, in. [CrossRef]

35. Ma, P.; Zhang, C.; Hong, X.; Xu, H. Pricing decisions for substitutable products with green manufacturing in a competitive supply chain. J. Clean. Prod. 2018, 183, 618-640. [CrossRef]

36. Yang, D.; Xiao, T.; Huang, J. Dual-channel structure choice of an environmental responsibility supply chain with green investment. J. Clean. Prod. 2019, 210, 134-145. [CrossRef]

37. Costantino, N.; Pellegrino, R. Choosing between single and multiple sourcing based on supplier default risk: A real options approach. J. Purch. Supply Manag. 2010, 16, 27-40. [CrossRef]

38. Govindan, K.; Fattahi, M.; Keyvanshokooh, E. Supply chain network design under uncertainty: A comprehensive review and future research directions. Eur. J. Oper. Res. 2017, 263, 108-141. [CrossRef]

39. Pellegrino, R.; Costantino, N.; Tauro, D. Supply chain finance: A supply chain-oriented perspective to mitigate commodity risk and pricing volatility. J. Purch. Supply Manag. 2019, 25, 118-133. [CrossRef]

40. McGuire, T.W.; Staelin, R. An industry equilibrium analysis of downstream vertical integration. Mark. Sci. 2008, 27, 115-130. [CrossRef]

41. Ghosh, D.; Shah, J. A comparative analysis of greening policies across supply chain structures. Int. J. Prod. Econ. 2012, 135, 568-583. [CrossRef] 
42. Liu, H.; Ji, S. Product selection and pricing policy of competitive supply chains considering consumers' green preference. Chin. J. Manag. 2017, 14, 451-458. (In Chinese)

43. Gao, J.; Han, H.; Hou, L.; Wang, H. Pricing and effort decisions in a closed-loop supply chain under different channel power structures. J. Clean. Prod. 2016, 112, 2043-2057. [CrossRef]

(C) 2020 by the authors. Licensee MDPI, Basel, Switzerland. This article is an open access article distributed under the terms and conditions of the Creative Commons Attribution (CC BY) license (http://creativecommons.org/licenses/by/4.0/). 